\title{
Translucent Concrete
}

\author{
Omkar Kadam \\ Department of Civil Engineering, Govt. College of Engineering Amravati, Maharashtra - 444604
}

\begin{abstract}
This article deals with the usage of translucent concrete and also the advantages it brings in the field of smart construction, that it can reduce the power consumption of illumination and use the optical fibre can be made to sense the stress of structures and this concrete as an architectural purpose for good aesthetical view of the building. Translucent concrete is a concrete based material with light-trans missive properties, obtained by embedding optical fibres in it. Light is conducted through the fibre from one end to the other. This results into a certain light pattern on the other surface, depending on the fibre structure. Optical fibres transmit light so effectively that there is virtually no loss of light conducted through the fibres. This type of concrete can be installed at average cost of construction and increasing the visual appearance of the building. The work presented in this project reports an investigation on the behaviour of concrete and mortar with optical fibre. Concrete and mortar cube are casted with fibres to study the properties and to compare the compressive strength between normal mix concrete with optical fibre and normal mortar with optical fibre after 7 days, 14 days and 28 days respectively. The compressive strength of concrete samples made with different fibre amount varies from $2 \%$ to $4 \%$ were studied. The compressive strength of translucent concrete is seen to increase with the increase in fibre content. The samples with fibres of $4 \%$ showed better results in comparison with the others.
\end{abstract}

\section{Introduction}

Today we are living in a world where energy expenditure and environmental problems have escalated to global scale. In today's developed world our built environment takes energy; energy to make the materials that go into the buildings, energy to construct them (Embodied energy) and energy to heat, cool \& light them (Operating energy). Countries with great population have buildings to be ratio higher than that of small population. Those buildings are isolated biosphere only based on manmade lights to maintain people's optical activities. For example, India consumes $20 \%$ of total electrical energy for lighting the buildings. Atpresent, green structures are greatly focusing on saving energy with indoor thermal systems. However, in area of illumination field, there is little research offering relevant solution. Research on intrinsic characteristic material which transmit the light from one surface to another surface is used as construction material which transmit the light from one surface to another surface is used as construction material, known as optical fibres. Due to its outstanding light guiding and sensing advantages, such as anti-electromagnetic Interference capability, small dimensions, distributed measurement and anticorrosion characteristics, optical fibres have been widely adopted in the communication and sensing fields. It is considered to be one of the best sensor materials available and has been used widely since the 1990s. Hungarian architect, Aron Losonczi, first introduced the idea of light transmitting concrete in 2001 and then successfully produced the first transparent concrete block in 2003, named LiTraCon as shown in Fig. 1.1.1 and 1.1.2. However, his transparent concrete did not have smart sensing properties[1].
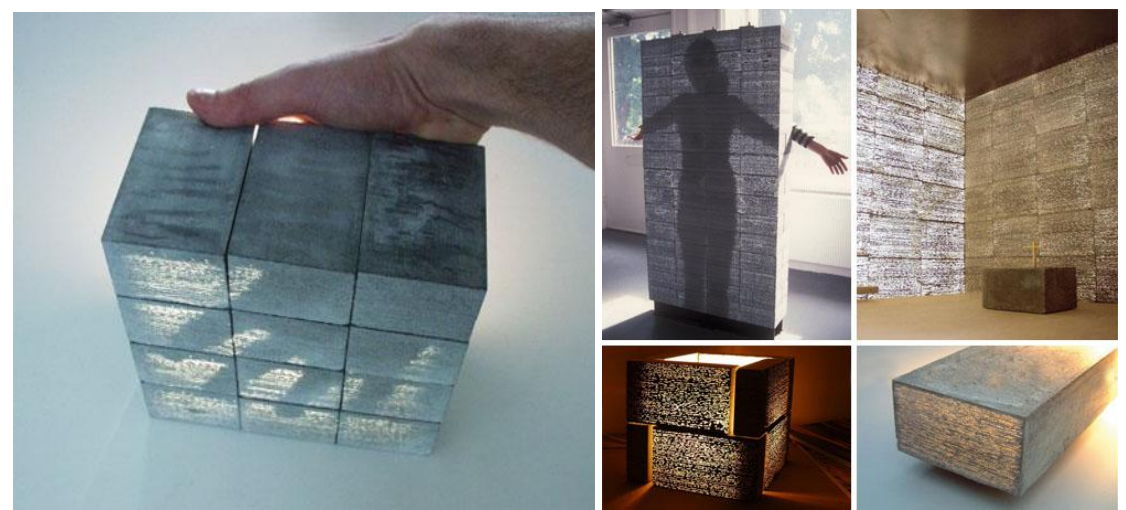

Fig. 1.1.1: LiTraCon 1Fig.1.1.2 : LiTraCon 2 


\subsection{Basic Purpose of Translucent Concrete}

In this seminar, a smart transparent concrete - novel construction material manufactured with Plastic Optical Fibre (POF) and Fibre Bragg Grating (FBG) by drillingthrough the cement and mortar in order to utilize the light guiding ability of POF and the sensing properties of FBG,respectively is studied. The main purpose is to use sunlight as a light source in order to reduce the power consumption ofillumination. Meanwhile, the steady sensing offered by FBG allows detection of potential internal deformation of theconcrete. Additionally, experiments to study the mechanical performance of the concrete infused with POF are studied.

The electric energy isderived primarily fromthermal power plants that are not clean sourcesand contribute to greenhouse gas emissions. An innovation liketranslucent concrete (TC) captures and delivers daylight into buildings, which could reduce our dependence on indoor lighting and saveelectricity. Such technology can be constructed as a part of a buildingenvelope (i.e., wall and roof), because it satisfies requirements that areusually set apart

- envelope behaving as a structural subsystem,

- construction procedure is simple and scalable, and

- Movable and mechanized parts are avoided.

Comparedwith a traditional electric lighting system, illuminating theindoors with daylight also creates a more appealing and healthyenvironment for building occupants[2].

Translucent Concrete is a combination of fibres optics and concrete. It can be produced as prefabricated building blocks and panels. Due to the small size of the fibres, they blend into concrete becoming a component of the material like small pieces of aggregate. Because of their parallel position of fibre, the lightinformation on the brighter side of a wall appears unchanged on the darker side. The sharp display of shadows will fall on the opposing side of the wall. Moreover, the colour of the light also remains the same. Thousands of optical fibres form a matrix and run parallel to each other between the two main surfaces of each block. These fibres mingle in the concrete because of their insignificant size, and they become a structural component as a kind of modest aggregate. Therefore, the surface of the blocks remains homogeneous concrete.

Translucent concrete is used in fine architecture as a facade material and for cladding of interior walls. Light-transmitting concrete has also been applied to various designproducts. When a solid wall is imbued with the ability to transmit light, it means that a home can use fewer lights in their house during daylight hours so it is energy saving.

With the economic growth and science and technology development, many large scale civil engineering structures such as tall buildings, underground buildings and landmark buildings and so on are built around the world. Those buildings are based on artificial lightings. Most of the large buildings are built close to each other, like sky scrapers. When many buildings are stacked close to each other, there is not much natural sunlight passing through and the importance of natural sunlight is well known. Translucent concrete comes in as a blessing solution for easier day lighting. By arranging many optical fibres into concrete it transmit light so effectively that there is virtually no loss of light conducted through the fibres.

The optical fibres have proper light guiding property and sensing advantages, such as small dimensions, distributed measurement and anti- corrosion characteristics, optical fibres have been widely adopted in the communication and sensing fields [3].

\subsection{Necessity of Using Fibre Optic Sensors in Concrete}

Concrete is one of the most frequent construction materials. Yet its durability is of major concern in terms of infrastructures in developed countries. Damage in concrete structures may be started at the early ages. In huge structures such as dams, high temperature drops which occur during the initial hydration may cause cracks. In long- term loading, environmental impacts can also cause dramatic failure. Highway bridges bearing heavy traffic, and subjected to freeze-and-thaw cycles are of familiar instances. For proper maintenance of concrete structures in their service life, it is essential to create sensors to monitor the structural conditions.

The use of fibre-optic sensors in concrete was first suggested by Mendez. Since then, several research groups in the USA and Europe have reported on a variety of fibre-optic sensors embedded in or attached to reinforced concrete structures. Many of these studies mainly emphasized on the measurement of strain vibration and temperature due to laboratory conditions. Optic fibres have been widely used in the field of data transmission due to their excellent anti-electromagnet sensing, little dimension and anti-corrosion qualities since 1970s POF are instruments to transmit light in the visible wave length based on specific structures in which the index reflecting is greater than reflect coating index so that the light can be transmitted to the full reflection, since in optical fibres core and cavity size are larger than in silicon dioxide, they are capable of absorbing light at an angle greater than 60 degrees and provide a better light transmitting system, so optic fibres can show the advantages of flexibility and plasticity in extremely unfavourable weather conditions. Transmitting light through the fibres as electromagnetic wave and some specific physical parameters (such as temperature, pressure, stress, strain, electric field, and magnetic field, etc) will affect the performance of the waves. 
Functions like amplitude phase, polarization state, frequency and physical state of output wave can be estimated by analyzing performance changes of the waves. Illuminated POF grids mixed with a certain proportion of cement namely transparent intelligent concrete provide novel clear view intelligent quality and long life structural material. It should be noted that the production of light transmitting concrete under the name of "Lightracan" was also done and recorded in Iran for the first time, and researchers were able to produce a high strength concrete with the capacity of transmitting synthetic and natural light through itself like the glass. Since the country is prone to earthquakes and the application of glass in facades can be very dangerous, the use of this type of concrete in buildings can be highly desirable, however, due to the lack of mass production of the industry, the application is only possible in some large buildings such as hotels, sport venues, aircraft, and hospitals, which can contribute to good light transmission absorbing heat energy and even as insulation in building in addition to its beauty [4].

\section{Materials}

There are two basic materials used for making transparent concrete, one is from construction field and another from sensing field. First, concrete is one of the most important civil engineering materials with the advantages of rich raw materials, low cost and simple production process and second the optical fibre has good light guiding property which can be arrange to transmit the light and the sun light transmit according to predesign road without light-heat, light-electrical or photochemical process, and photo elastic effect which can be used to study the stress distribution of structures. Combining the advantages of the concrete and optical fibre, developing a novel functional material called transparent concrete has an important value in the application of construction and sensing[5].

\subsubsection{Optical Fibre}

An optical fibre is a flexible, transparent fibre made of silica or plastic, slightly thicker than a human hair. It functions as a waveguide or light pipe, to transmit light between the two ends of the fibre. The field of applied science and engineering concerned with the design and application of optical fibres is known as fibre optics. Optical fibres are widely used in fibre-optic communications, which permits transmission over longer distances and at higher bandwidths .Fibres are used for illumination, and are wrapped in bundles so that they may be used to carry images, thus allowing viewing in confined spaces. Specially designed fibres are used for a variety of other applications, including sensors and fibre lasers. Optical fibres typically include a transparent core surrounded by a transparent cladding material with a lower index of refraction as shown in Fig. 2.1.1. Light is kept in the core by total internal reflection. This causes the fibre to act as a waveguide.

Fibres that support many propagation paths or transverse modes are called multi-mode fibres (MMF), while those that only support a single mode are called single-mode fibres (SMF). Multi-mode fibres generally have a wider core diameter, and are used for short-distance communication links and for applications where high power must be transmitted.

Optical fibre is a transparent and flexible material made of silica. This optical fibre helps to transmit light in the cube from one end to other end. The percentage of optical fibre used for the study is $2 \%$ by volume.

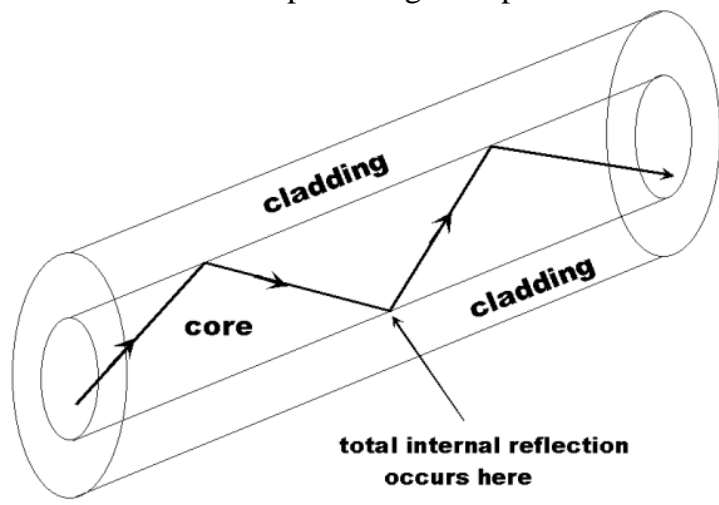

Fig2.1.1 : Optical Fibre

Optical fibres work as a cylindrical waveguide that transmits light along its axis, by the process of internal reflection. Optical fibre has good light guiding property which can be arrange to transmit the light and the sun light transmit according to pre- design road without light-heat, light-electrical or photochemical process, and photo elastic effect which can be used to study the stress distribution of structures. Combining the advantages of the concrete and optical fibre, developing a novel functional material called transparent concrete has an important value in the application of construction and sensing. 


\subsubsection{Principle of Operation}

Transparent concrete or translucent concrete is work Based on "Nano-Optics". Optical fibres passes as much light when tiny slits are placed directly on top of each other as when they are staggered. Principal can carry because optical fibres in the concrete act like the slits and carry the light across throughout the concrete.

The fibre will change the interior appearance of buildings by illuminating them and better appearance. The main purpose of using optical fibre is that it can transmit light. Plastic Optical Fibre (POF) can with stand harsh environment and has a higher ductility and good flexibility property. POF transmits light in the form of electromagnetic waves whose properties like amplitude, phase, polarised state and frequency are directly influenced / affected by physical parameters like pressure, strain, stress, electric field, temperature and magnetic field. Optical fibre is a three layered cable, buffer coating, cladding and core are the inner layers of the fibre and the light transmissions carried out through the core of the fibre[5].

\subsubsection{Material Specification}

The basic material used for manufacture of transparent concrete are cement, aggregate and optical fibre. Table 2.2.1 shows the important specifications of this materials.

Table2.2.1 :Material Specification [3]

\begin{tabular}{|l|l|l|}
\hline Sr. & Material & Specifications \\
\hline 1 & Cement & 53 Grade \\
\hline 2 & Coarse aggregate & Less than $10 \mathrm{~mm}$ \\
\hline 3 & Fine aggregate & Passing through $2.36 \mathrm{~mm}$ sieve \\
\hline 4 & Concrete & M 20 Grade \\
\hline 5 & Optical fibre & $2 \%-4 \%$ \\
\hline
\end{tabular}

\subsubsection{Properties of Materials}

- Cement

Ordinary Portland cement was used for casting all the specimens. The important features required in translucent concrete are shown in Table 2.2.2.1

Table 2.2.2.1 :Properties of Cement [3]

\begin{tabular}{|l|l|l|}
\hline Sr. & Properties of Cement & Values obtained \\
\hline 1 & Fineness of cement as retained on 90 micron sieve & $3 \%$ \\
\hline 2 & Grade of cement & 53 \\
\hline 3 & Specific Gravity & 3.15 \\
\hline 4 & Initial Setting time & $30 \mathrm{~min}$ \\
\hline
\end{tabular}

- Fine Aggregate

Clean and dry river sand available locally is used. Sand passing through IS $4.75 \mathrm{~mm}$ Sieve is used for casting all the specimens. The values of specific gravity and fineness modulus are shown in Table 2.2.2.2.

Table 2.2.2.2 :Properties of Fine Aggregate [3]

\begin{tabular}{|l|l|l|}
\hline Sr. & Properties & Values obtained \\
\hline 1 & Specific Gravity & 2.53 \\
\hline 2 & Fineness Modulus & 2.64 \\
\hline
\end{tabular}

- Coarse Aggregate:

Coarse aggregate passing through $10 \mathrm{~mm}$ sieve is used for casting all specimens. Table 2.2.2.3 indicates the important values of properties of coarse aggregate.

Table2.2.2.3 :Properties of Coarse Aggregate [3]

\begin{tabular}{|l|l|l|}
\hline Sr. & Properties & Values \\
\hline 1 & Size of Aggregates & $10 \mathrm{~mm}$ \\
\hline 2 & Fineness Modulus & 5.01 \\
\hline 3 & Specific Gravity & 2.35 \\
\hline
\end{tabular}

- Water:

Ordinary potable water of normally $\mathrm{pH} 7$ is used for mixing and curing the concrete specimen [3].

\subsection{Summary}

There are two basic materials used for making transparent concrete, one is from construction field and another from sensing field. First, concrete is one of the most important civil engineering materials with the advantages of rich raw materials, low cost and simple production process and second the optical fibre has good

DOI: 10.9790/1684-1403031831 $\quad$ www.iosrjournals.org $\quad 21 \mid$ Page


light guiding property which can be arrange to transmit the light and the sun light transmit according to predesign road without light-heat, light-electrical or photochemical process, and photo elastic effect which can be used to study the stress distribution of structures. Combining the advantages of the concrete and optical fibre, developing a novel functional material called transparent concrete has an important value in the application of construction and sensing.

\section{Manufacturing Process, Test Results And Properties}

Transparent concrete is produced out of fine-grain concrete and translucent fabric which is layer cast in pre-fabricated mould. Because of relatively small amount of fabric, solidity and consistency of transparent concrete are the same as the high-strength concrete. Almost free energy loss light penetration through optic fibres makes it possible to see light, shadows and even colours through concrete even by very thick walls. It can be produced as prefabricated building blocks and panels. Due to the small size of the fibres, they blend into concrete becoming a component of the material like small pieces of aggregate. In this manner, the result is not mixed material like glass in concrete but a new material, which is homogeneous in its inner structure as well as on its main surfaces. The optical fibres lead light by points between the two sides of the blocks. Because of their parallel position, the light-information on the brighter side of such a wall appears unchanged on the darker side. The most interesting form of this phenomenon is probably the sharp display of shadows on the opposing side of the wall. Moreover, the colour of the light also remains the same [6].

\subsection{Basic Procedure}

The manufacturing process of transparent concrete is almost same as regular concrete. Only optical fibres are spread throughout the aggregate and cement mix. Small layers of the concrete are poured on top of each other and infused with the fibres and are then connected. Thousands of strands of optical fibres are cast into concrete to transmit light, either natural or artificial. Light-transmitting concrete is produced by adding $4 \%$ to $5 \%$ optical fibres by volume into the concrete mixture. The concrete mixture is made from fine materials only it does not contain coarse aggregate. Thickness of the optical fibres can be varied between $2 \mu \mathrm{m}$ and $2 \mathrm{~mm}$ to suit the particular requirements of light transmission. Automatic production processes use woven fibres fabric instead of single filaments. Fabric and concrete are alternately inserted into moulds at intervals of approximately $2 \mathrm{~mm}$ to $5 \mathrm{~mm}$.Smaller or thinner layers allow an increased amount of light to pass through the concrete. Following casting, the material is cut into panels or blocks of the specified thickness and the surface is then typically polished, resulting in finishes ranging from semi-gloss to high-gloss [5].

- Cement Mixing:-Very fine aggregate is mixed with Portland cement of variable compressive strength concrete. Sand: cement: water ratio is 1:2:0.44. The concrete mix is then placed in mould of required size.

Mix Ratio Of Concrete - $1.0: 1.5: 3.0$

Mix Ratio Of Mortar - $1.0: 3.0$

- Placement of Optical Fibre:-Optical fibre is then stretched in machine and with help of that machine the optical fibres are inserted in fresh concrete just after placing fresh concrete in mould as shown in Fig. 3.1.1. Optical fibre are inserted in such a way that their some of the endings part is outside the concrete.
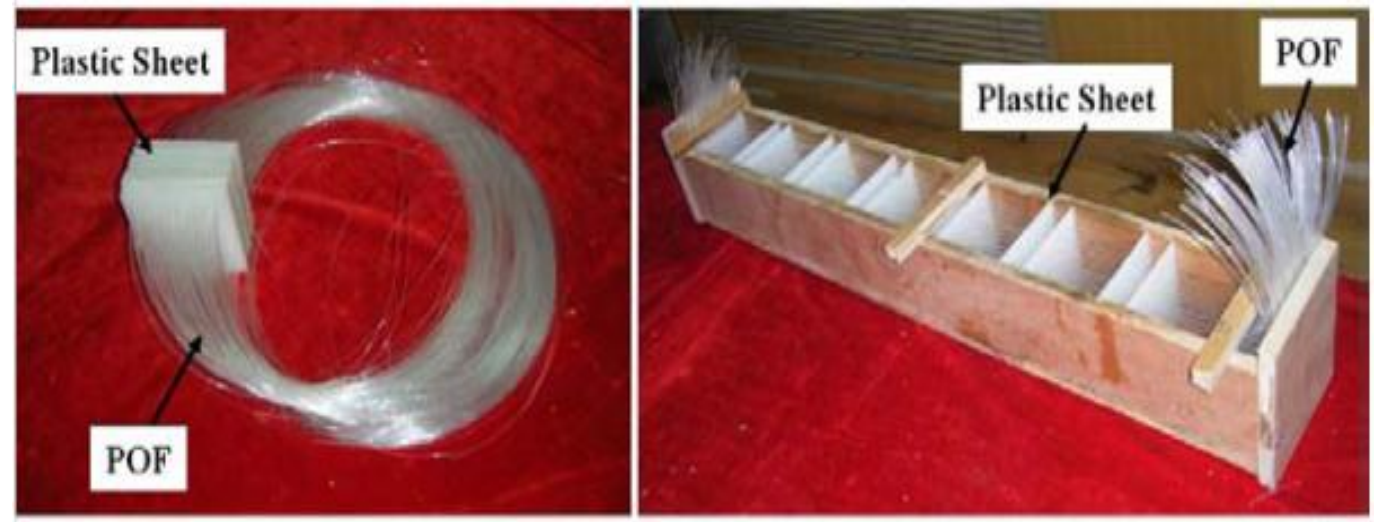

Fig.3.1.1 : Placement of Optical Fibre [7]

- Cutting:-Edges of fibre from the surface of concrete block are by cutting machine.

- Finishing:-The surface obtain after cutting of edge of fibre optics is quit rough, for smoothing of surface finishing is done. After all the above processes the finished concrete looks like as shown in Fig. 3.1.2[7]. 

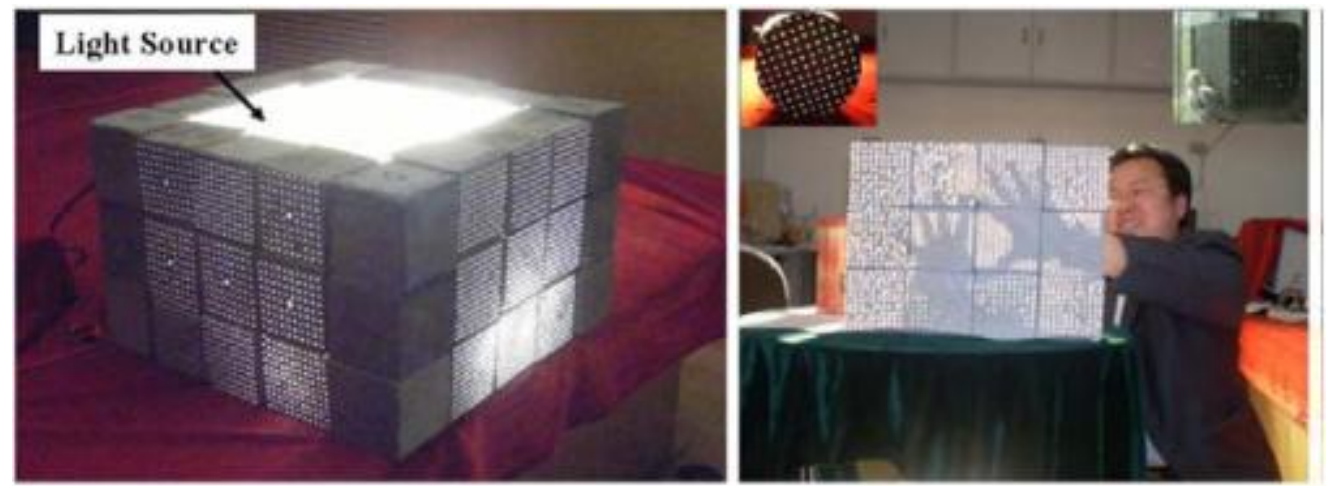

Fig.3.1.2 :Finishing

\subsection{Results Of Experimental Investigations \\ 3.2.1Compressive Strength Results}

The results of POF $1.5 \mathrm{~mm}$ diameter for various volume fraction is shown in Fig. 3.2.1.1. The obtained results indicated that the compressive strength at 7 days age decreases asfibre content increases, Where the decrease was about $(24.5,29.5$ and $33.4 \%)$ for $(2,3,4 \%)$ fibre volume fraction content respectively as compared with reference sample without POF. While at 28 and 90 days age the compressive strength improved due to thehydration of cement development of interfacial transition zone between the matrix andthe POF. So that the results show the compressive strength decreased by about $(23.2,16.3$ and $14.2 \%)$ for $(2,3$ and $4 \%)$ fibre volume fraction content respectively as comparedwith reference sample without POF and the same trend is observed at 90 days age this mains that the inclusion of POF in the matrix did not affect the compressive strengthsignificantly.

The compressive strength of POF 2.0 mm diameter in Fig. 3.2.1.2 shows a decrease whenfibre content increased for all ages, and the decrease in compressive strength at 7 daysage is (15.4, 25.5and 29.5\%) for $(2,3$ and $4 \%)$ fibre volume fraction content respectively as compared with referencesample without POF. and $(2.8,9.8$ and $26.0 \%))$ at 90 days for $(2,3$ and $4 \%)$ fibre volumefraction content respectively as compared with reference sample without POF. In thesame context, the results show that the POF $2.0 \mathrm{~mm}$ diameter samples have the highestcompressive strength at different fibre concentration and diameters.From the compressive strength results of POF $3.0 \mathrm{~mm}$ as shown in Fig.3.2.1.3 thedifference between the compressive strength at 7 days age and the compressive strengthat the 90 days age decreased from (30.6, 31.7and 35.3\%) to (21.9, 24.3 and $28.0 \%$ ) for 2 , 3and $4 \%$ fibrevolume fraction content respectively as compared with reference samplewithout POF. And it can be seen that the POF $3.0 \mathrm{~mm}$ diameter also decreases with POF content, but inthe case of $4 \%$ POF content we can see an increase in compressive strength due to theuneven distribution of $\mathrm{POF}$ in concrete and indicates that the irregular distributionweakened the structure of the concrete.

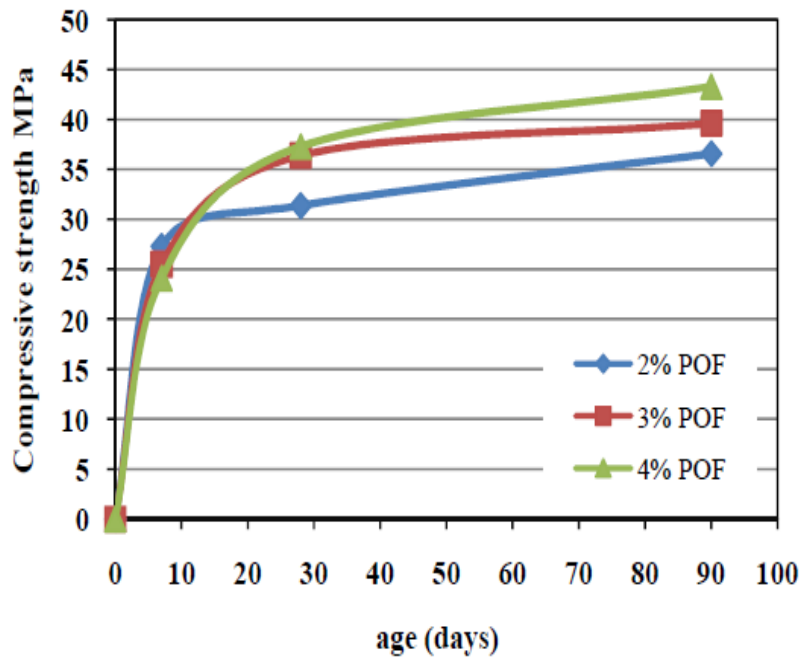

Fig.3.2.1.1 :Relation Between Compressive Strength and time(1.5mm diameter) [8] 


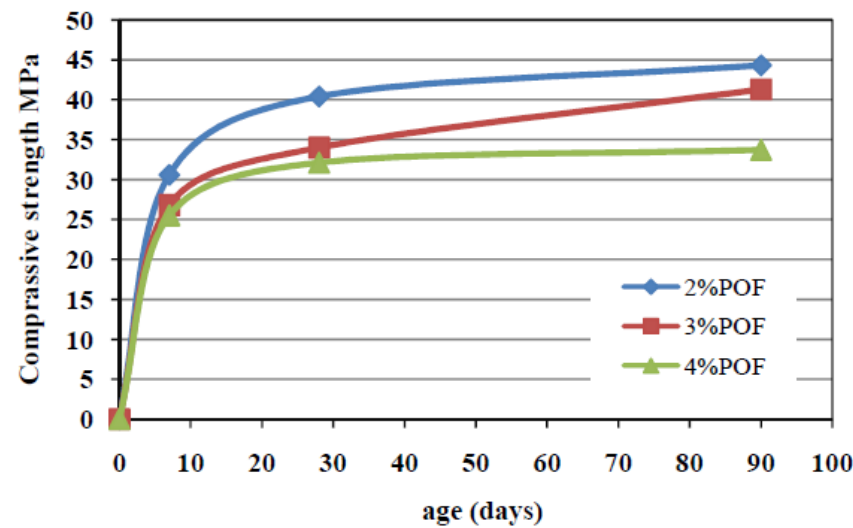

Fig .3.2.1.2 :Relation Between Compressive Strength and time( $2 \mathrm{~mm}$ diameter) [8]

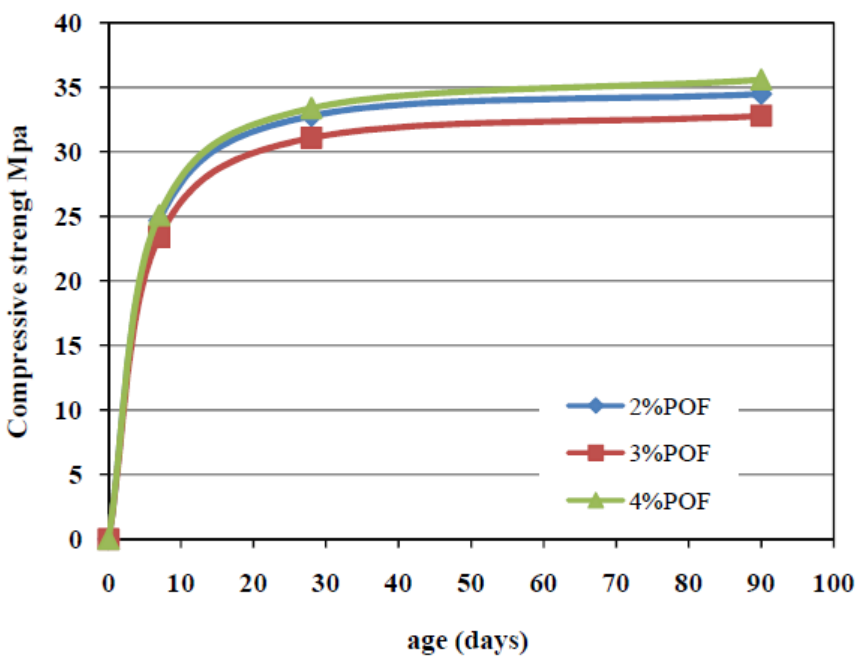

Fig .3.2.1.3: Relation Between Compressive Strength and time(3 mm diameter) [8]

\subsubsection{Flexure Strength Results}

The flexure strength of POF 1.5, 2.0 and $3.0 \mathrm{~mm}$ diameter for various volume fractions isshown in Fig.3.2.2.1 for 7 days age and is compared with reference samples withoutPOF. It's noticed that flexure strength is slightly decreased with fibre volume fractioncontent for all the POF diameters, and that the $1.5 \mathrm{~mm}$ diameter of POF has the highest value at 7days age. It's noticed that the failure occurred in interfacial transition zonebetween the POF and cement paste and occurred partly through the cement past andthrough the interfacial transition zone. This behaviour is due to the smoothness of theoptical fibre surface which leads to this type of surface of fraction. We can also see thepercentage of the flexural strength reduction between (15.00 to $47.30 \%$ ) for variousdiameters and fibre volume fractions content. But, the test results improved with age ofsamples at 28 as seen in Fig. 3.2.2.2. This indicates that the $2.0 \mathrm{~mm}$ POF diameter have the highest value reached about $(8.11,7.7$ and7.11MPa) for (2,3 and 4\%) fibre volume fraction content respectively for 90days age[8].

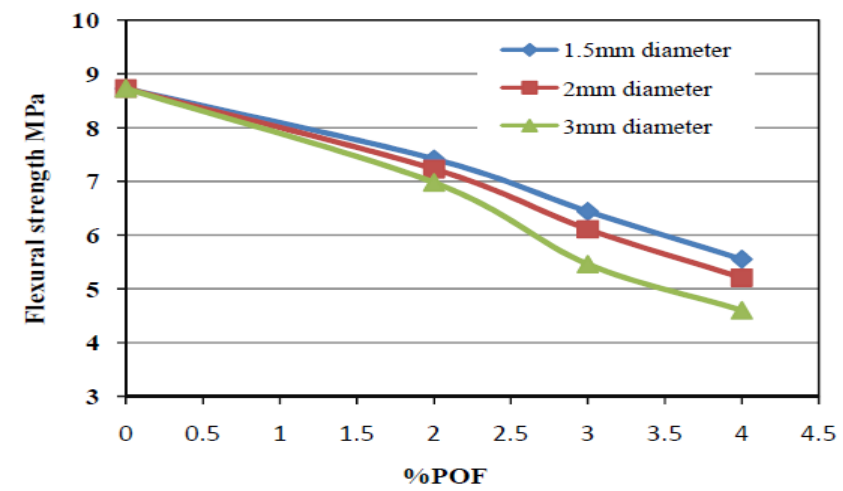

Fig.3.2.2.1 :Relation Between Flexural strength and \% POF (7 days) [8] 


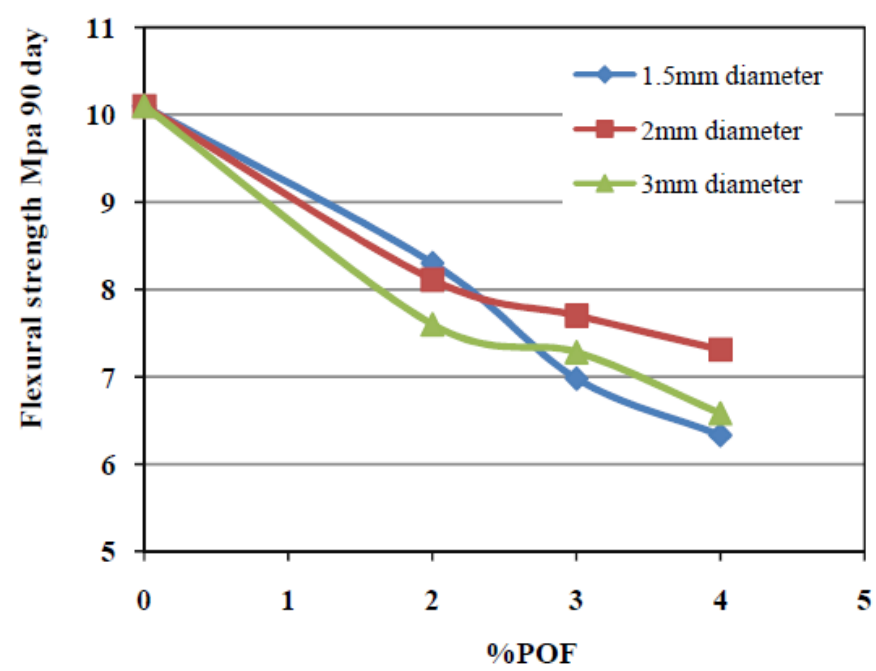

Fig.3.2.2.2 :Relation Between Flexural strength and \% POF (90 days) [8]

\subsubsection{Self-Sensing Property of Smart TC Based On Stress Elasto-Optic Effect}

Glass fibre is a kind of photo elastic material, which is isotropic under normal circumstances. Once be applied load, glass fibre becomes anisotropic, and light birefringence phenomena in it is generated. Commonly, if the optical constants and thickness of glass fibre, the isochromatics and isoclinic's are known, the stress state of the glass fibre can be obtained based on the shear difference method. Based on this phenomenon, glass fibre is layout into the smart transparent concrete to monitor the stress state of structures, and the glass fibre can be considered as a sensing element and an optical transmission material. In order to study the self-sensing property of smart transparent concrete, we simultaneously layout a glass fibre with $15 \mathrm{~mm}$ diameter and numbers of POFs into the concrete with the size of. In the test, the isochromatics and the isoclinic of the samples are gotten by using the plane polarized light and circularly polarized light equipments respectively. Fig. 3.2.3.1 shows the experimental setup including a glass fibre or a smart transparent concrete, a loading device and a photo elasticity experimental equipment. The circularly polarized optical field is obtained by adding two $1 / 4 \lambda$ wave plates in the plane polarized optical field. The strain applied on the samples is recorded by the strain gauge pressure transducer.

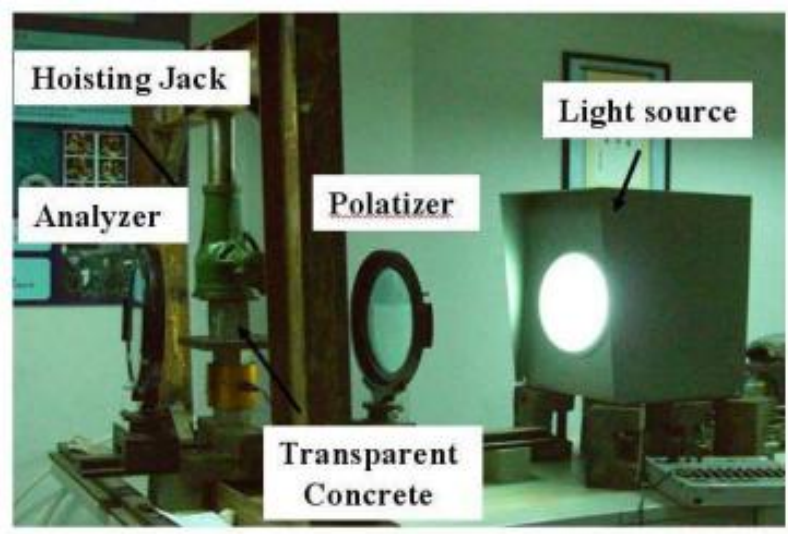

Fig.3.2.3.1 :Photo Elasticity Experimental Equipment [9]

\subsubsection{Test of Self-Sensing Property of Smart Transparent Concrete Based on Stress Elasto-Optic Effect Using 3 Moulds}

Fig..3.2.4.1(a) shows the smart transparent concrete with size of $100 \mathrm{~mm} \times 100 \mathrm{~mm} \times 100 \mathrm{~mm}$ by combining with glass fibre and POFs. The diameters of glass fibre and POF are $15 \mathrm{~mm}$ and $2 \mathrm{~mm}$ respectively. The glass fibre is considered as a stress sensing element in the concrete. The isochromatics and the isoclinic's of the glass fibre are monitored under plane/ circularly polarized optical field, which can reflect the stress state of the concrete. In order to test the self-sensing properties of the smart transparent concrete, the elasto-optic effect of the transparent concrete under different damage modes are studied. Fig 3.2.4.1(b) shows the damage modes of concrete, where a crack with size of $0.5 \mathrm{~mm}$ is produced. Fig. 3.2.4.2 gives three loading modes: a) un- 
damage mode (I); b) "longitudinal" damage mode (II); c) "lateral" damage mode (III). The "longitudinal" damage mode is that the crack is parallel to the loading direction, and the "lateral" damage mode is that the crack is vertical to the loading direction.[9]

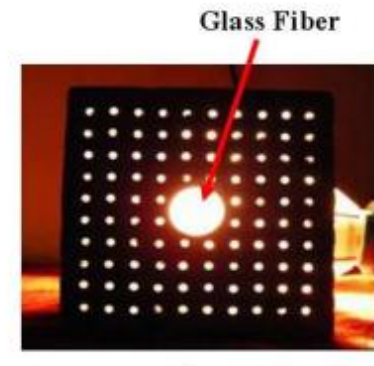

a)

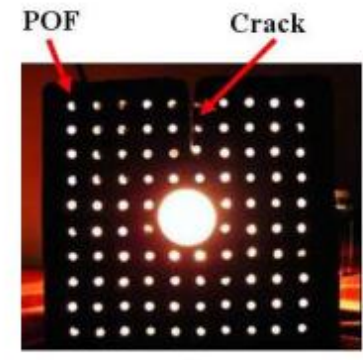

b)

Fig. 3.2.4.1Non-damage and damage samples of transparent concrete with glass fibre [9]

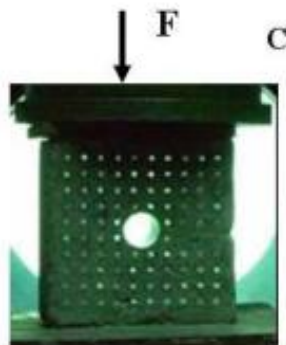

a)

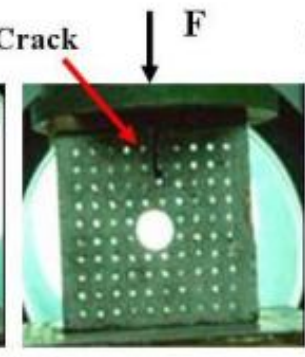

b)

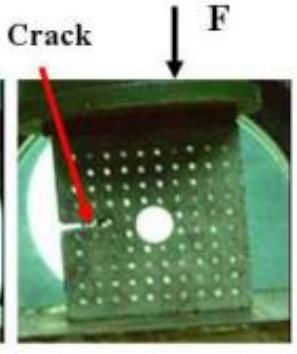

c)

Fig. 3.2.4.2 Three loading modes for smart transparent concrete [9]

\subsubsection{Transmitting Performance of the Smart Transparent Block}

The transmitting performance of the smart transparent block was tested similar to that used for theepoxy resin-based block. In considering the distribution of the lighttransmitting features of the transparent concrete block, it is observed that the light transmitting ratio becomes higher witha higher column proportion of $\mathrm{POF}$ and is stable at certain proportions of POF in concrete. Fig 3.2.5.1 shows the mould used for casting smart concrete block.

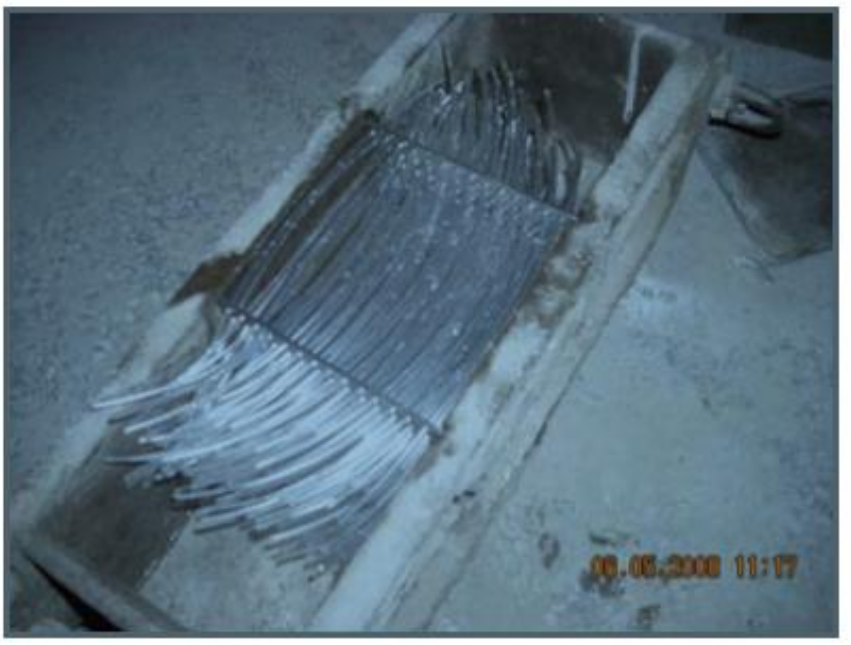

Fig. No. 3.2.5.1 Themould for a smart concrete block [10]

\subsubsection{Mechanical Performance of the Smart Transparent Block}

To investigate any influence of the POF on the strength of the transparent concrete block, a compression test was carriedout for each specimen, as illustrated in Fig.3.2.6 The test data is shown in 
Table.3.2.6. It can be observed that the volume proportion affects the compression strength of the concrete block for less than $10 \%$ when the proportion ratio of the POFis less than 5 percent[10].

Table3.2.6: Mechanical performance of the smart concrete block [10]

\begin{tabular}{|l|l|l|l|l|}
\hline Proportion & $0.00 \%$ & $3.14 \%$ & $3.80 \%$ & $4.52 \%$ \\
\hline \multirow{5}{*}{ Test data $(\mathrm{kN})$} & 190.5 & 190 & 219 & 180.5 \\
\cline { 2 - 5 } & 220 & 228 & 194 & 182 \\
\cline { 2 - 5 } & 195 & 185 & 174 & 184 \\
\hline Average & 201.8 & 201 & 195.7 & 182.2 \\
\hline
\end{tabular}

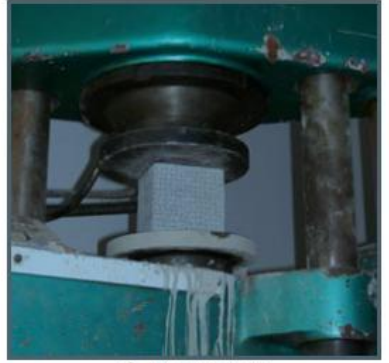

a) Test setup

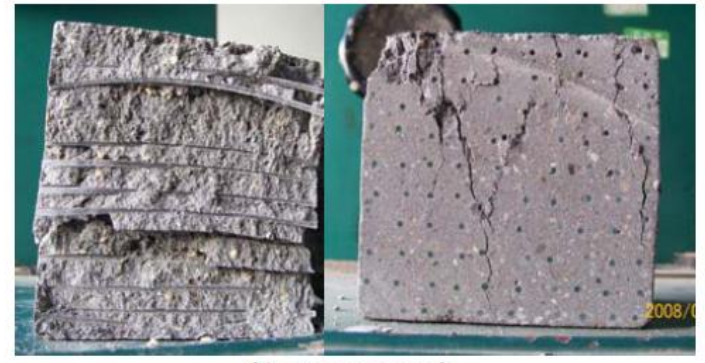

b) Damage mode

Fig. 3.2.6 Mechanical performance of the smart concrete block [10]

\subsection{Properties Of Translucent Concrete}

Following are the important properties of translucent concrete that makes it advantageous over ordinary concrete.

\subsubsection{Durability Property of Smart Transparent Concrete}

Civil engineering structures always suffer from external environmental effects, such as fatigue, corrosion and wind load and so on, in long-term service. Mechanical property and anti-corrosion property of building material at adverse environments are two key facts for the durability of in-service structures, which directly impact the safety of structures[9].

\subsubsection{Impermeability Property of Smart Transparent Concrete}

For the smart transparent concrete, the interfacial bonding of the POFs and concrete is a crucial factor in determining ultimate impermeability properties. The chloride diffusion coefficient method (or electric flux method) is used to test the impermeability property of smart transparent concrete, which can rapidly evaluate the permeability of concrete by measuring the electric energy through concrete. In this paper, the smart transparent concretes with $0 \%, 3 \%$ and $6 \%$ POF volume ratio are chosen for the test. The electric energy is recorded by the electric flux detector NJW-RCP-6A made in China, and cylindrical concrete specimens with $100 \mathrm{~mm}$ diameter and $50 \mathrm{~mm}$ height are fabricated from the prefabricated smart transparent concretes by core-drilling method, shown as Fig.3.3.2.1 Moreover, in order to evaluate the effect of interface bonding on the impermeability property, each model of specimen has been divided two types. One is that the border of POF and concrete is covered by epoxy resin, the other one is not covered by epoxy resin, as shown in Fig.3.3.2.1. Fig. 3.3.2.2 shows the test configuration. The process of permeability test based on the electric flux method can be described in Fig. 3.3.2.3.

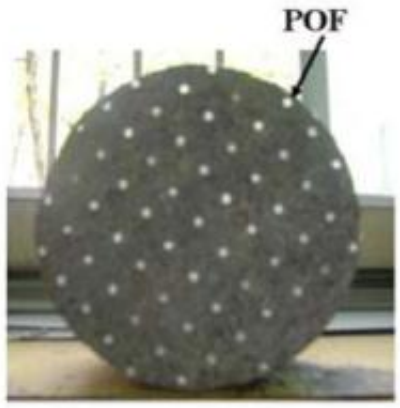

a) Not Covered by Epoxy Resin

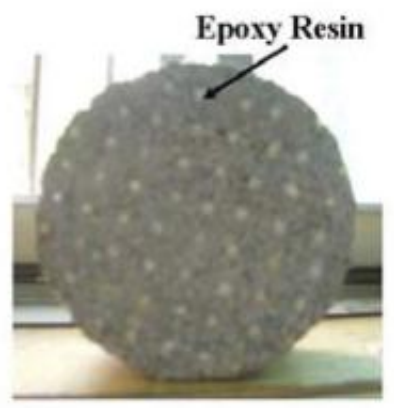

b) Covered by Epoxy Resin

Fig. 3.3.2.1 Cylindrical concrete specimens for impermeability [1] 


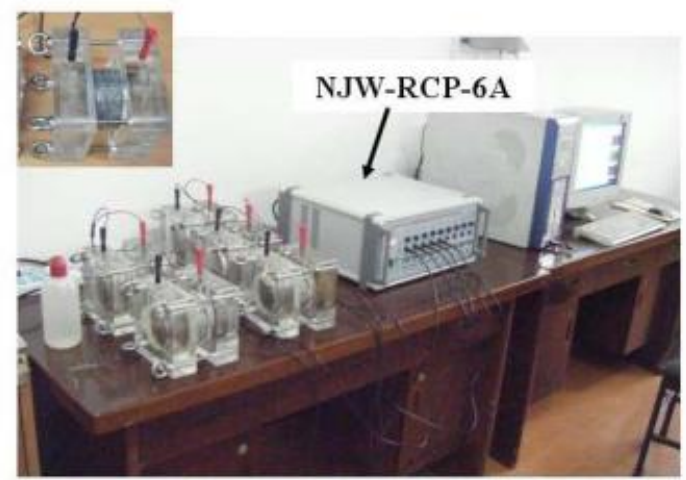

Fig. 3.3.2.2 Setup of test [1]

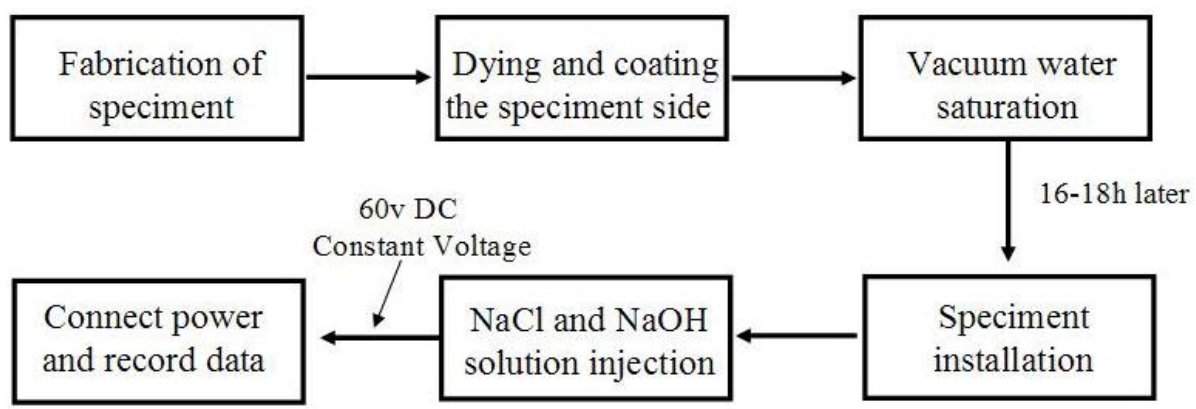

Fig. 3.3.2.3 Procedure of chloride diffusion coefficient test [1]

\subsubsection{Impermeability Property of Smart Transparent Concrete over Time}

Fig. 3.2.3.1 shows the relationship of current strength over time. After the vacuum water saturation, the initial current strength of the plain concrete, the smart transparent concrete with 3\% POF volume ratio, the smart transparent concrete with 3\% POF volume ratio and POF covered by epoxy resin, the smart transparent concrete with 6\% POF volume ratio and the smart transparent concrete with 6\% POF volume ratio and POF covered by epoxy resin are $70.4 \mathrm{~mA}, 104.5 \mathrm{~mA}, 79 \mathrm{~mA}, 117 \mathrm{~mA}$ and $114.9 \mathrm{~mA}$, respectively. After six hours conduction time, the corresponding current strengths of the above six concretes increase to $113.6 \mathrm{~mA}, 181.7 \mathrm{~mA}, 126.4 \mathrm{~mA}$, 201.6mA and 1944.2mA, respectively.
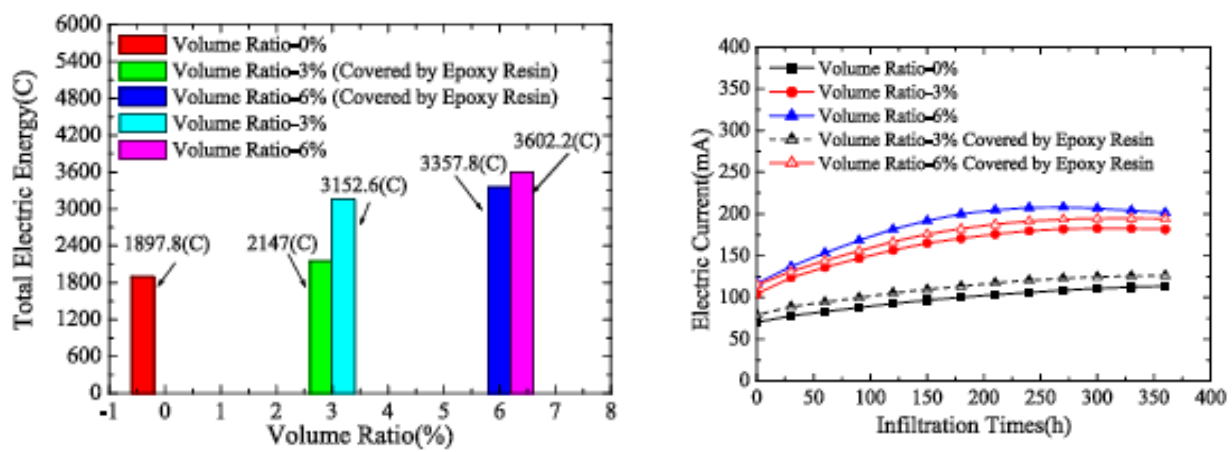

Fig. 3.3.3.1 The Relationship of TotalFig. 3.3.3.2 Comparison total electric energy Current Strength Over Time [1] traversing the smart concrete[1]

The total electric energy of the plain concrete, the smart transparent concrete with $3 \%$ POF volume ratio and that with $6 \% \mathrm{POF}$ volume ratio are $1897.8 \mathrm{C}, 3152.6 \mathrm{C}$ and $3602.2 \mathrm{C}$, that is, there are some minor gaps between the POFs and concrete which cause the decrease of the anti-permeability shown in figure 24. It also can be seen that the anti-permeability is greatly improved by using the epoxy resin to cover the boundary of the POFs and concrete, and the total electric energy of the smart transparent concrete with $3 \%$ and $6 \%$ POF volume ratio covered by epoxy resin are reduced to $2147 \mathrm{C}$ and $3357.8 \mathrm{C}$. In field application, the anti-permeability index of smart transparent concrete is very important for the long-term service. We can improve the anti-permeability 
by two methods: one is to seal the boundary of POFs and concrete with transparent waterproof material such as epoxy resin; the other one is to make the POF's coating rough to increase the compactness of interface between the POF and concrete [1].

\subsection{General Properties Of Translucent Concrete}

Following Table 3.4 shows different properties of transparent concrete blocks.

Table 3.4 Properties of Translucent Concrete.[11]

\begin{tabular}{|l|l|}
\hline Properties of Transparent Concrete Specimens & Translucent Concrete \\
\hline Form & Prefabricated \\
\hline Ingredients & $96 \%$ concrete, $4 \%$ optical fibre \\
\hline Density & $2100-2400 \mathrm{Kg} / \mathrm{m} 2$ \\
\hline Block size & $600 \times 300 \mathrm{~mm}$ \\
\hline Thickness & $25-500 \mathrm{~mm}$ \\
\hline Colour & White, Grey or Black \\
\hline Fibre distribution & Organic \\
\hline Finished & Polished \\
\hline Compressive strength & $50 \mathrm{~N} / \mathrm{mm} 2$ \\
\hline Bending Tensile strength & $7 \mathrm{~N} / \mathrm{mm} 2$ \\
\hline
\end{tabular}

\section{Applications}

The main advantage of transparent concrete is that it can transmit light. There, it can be used to make green buildings. Since it can transmit light from natural as well as artificial sources, the building can have fewer lights to meet its demand for lighting. Thus saving huge energy cost.

Transparent concrete uses sunlight as source of light instead of electrical energy and reduces power consumption. This concrete can also be used cold countries to transmit heat with sunlight. Translucent concrete is not currently widely produced. There are only a select few companies, and the process is somewhat low-tech and slow. It can only be produced as pre-cast or prefabricated blocks and panels; it cannot be poured on site like traditional concrete. The blocks come in a range of sizes, the maximum for glass fibre being $1200 \times 400 \mathrm{~mm}$ (47.2 $\times 15.7$ inches), and the thickness can range from $25-500 \mathrm{~mm}$ (1-20 inches). This allows translucent concrete to be used for a variety of purposes, from a thin veneer to a structural system. According to one German company, it can be used "for ventilated facade systems as well as for interior cladding". So far translucent concrete has been used to make light installations, signs, and fixed-in-place furniture such as benches, desks, and counters. In its early days, it was used mostly in art installations and material demonstrations such as the Liquid Stone exhibit at the National Building Museum, and a sidewalk in Stockholm that looked "like an ordinary sidewalk by day but illuminated at night by lights under it". It is presently used mostly in interiors as decoration, but is making its foray into exterior structural walls[12].

\subsubsection{Walls}

Transparent Concrete can be used as building material for interior and exterior walls. If sunshine illuminates the wall structure, then eastern or western placement is recommended; the rays of the rising or setting sun will hit the optical glass fibres in a lower angle and the intensity of the light will be bigger. Besides the traditional applications of a wall, the light transmitting concrete can also be used as wall covering illuminated from the back. Also in some cases roof can be designed in creative way by using translucent concrete as shown in Fig. 4.1.1.

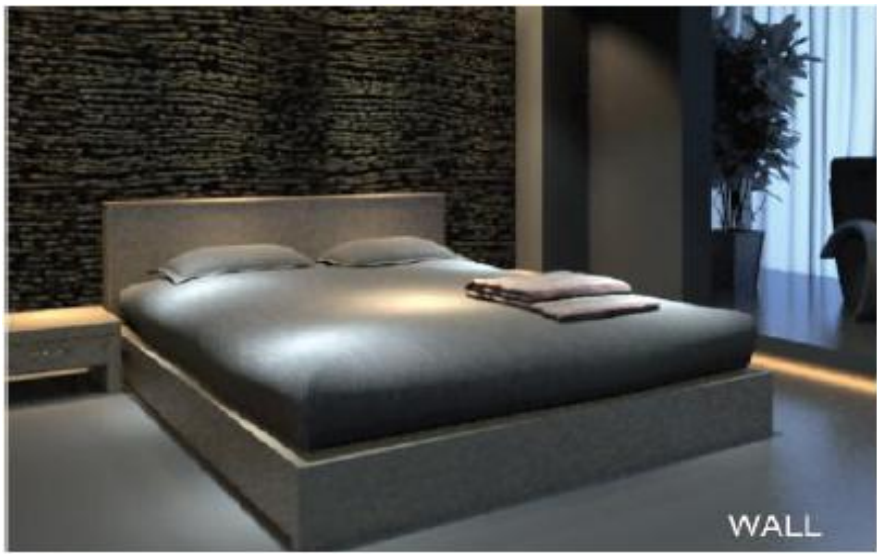

Fig.4.1.1 :Translucent Roof 


\subsubsection{Pavement}

This concrete can be used as flooring a passable surface illuminated from below. During the day it looks like typical concrete pavement but at sunset the paving blocks begin to shine and in different colours.

\subsubsection{Creative Design}

The building units are versatile and can be used in many areas of design. Two successful designs using the light transmitting concrete were a jewel and a concrete bench. You can also create a logo with colourful figures, inscriptions, and pictures and can used for beautification purpose. Fig 4.1.3 shows one of the creative designs of translucent concrete.

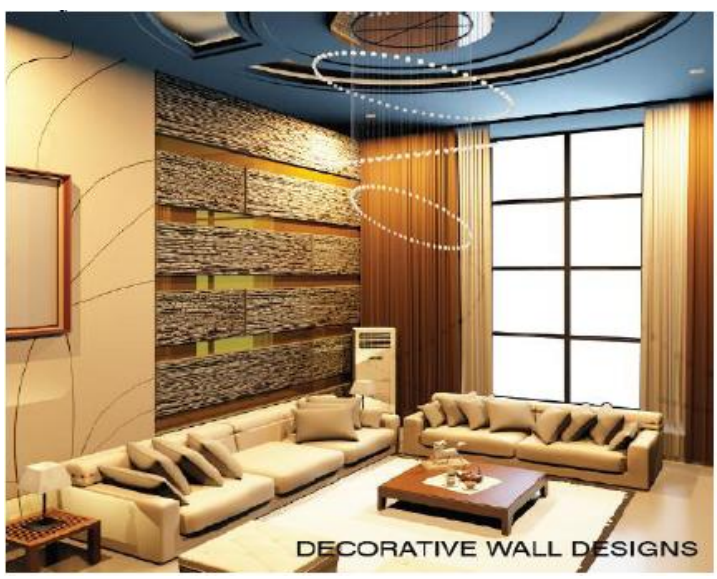

Fig. 4.1.3: Translucent Wall

\subsubsection{Desk}

If you really want to create a look that stands out, you should opt for this artsy and vogue reception desk where light up in the front and the sides.

\subsubsection{A Lighting Fixture and Conversational Piece}

The transparent concrete cube is, without a doubt, a great conversation piece. The new cube line consists of four identical pieces of concrete and, due to its special geometry; the pieces form a stable structure without fixing them together.

\subsubsection{Other Applications}

It can be also applicable at:

- Transparent concrete blocks suitable for floors, pavements and load-bearing walls.

- Facades, interior wall cladding and dividing walls based on thin panels.

- Partitions wall and it can be used where the sunlight does not reach properly.

- In furniture for the decorative and aesthetic purpose.

- Light fixtures.

- Light sidewalks at night.

- Increasing visibility in dark subway stations.

- Lighting indoor fire escapes in the event of a power failure.

- Illuminating speed bumps on roadways at night [5]

\subsection{Advantages And Disadvantages}

The main advantage of these products is that on large scale objects the texture is still visible - while the texture of finer translucent concrete becomes indistinct at distance.

- When a solid wall is imbued with the ability to transmit light, it means that a home can use fewer lights in their house during daylight hours.

- It has very good architectural properties for giving good aesthetical view to the building.

- Where light is not able to come properly at that place transparent concrete can be used.

- Energy saving can be done by utilization of transparent concrete in building.

- Totally environment friendly because of its light transmitting characteristics, so energy consumption can be reduced.

- The main disadvantage is these concrete is very costly because of the optical fibres.

- Casting of transparent concrete block is difficult for the labour so special skilled person is required [5]. 


\section{Conclusions}

A novel construction material named smart transparent concrete was developed using POF and FBG. The light transmitting, mechanical properties and self-sensing performance were cautiously investigated and the stated hypothesis of its light guiding capability was confirmed. FBG arranged in concrete can sense the inner deformation of concrete specimens under such research and experimentation provides solid evidence for the intelligence of this system in structural safety assessment. With regard to the energy-saving aspect, POF-based concrete allows the use of sunlight for illumination; in the case of emergencies, transparent concrete will provide some relief in the case of daytime power outage for skyscrapers, making evacuation safer and more efficient. Additionally, a smart transparent concrete is aesthetically pleasing. POF-based transparent concrete could be regarded as an art which could be used in museums and specific exhibitions rather than just a construction material.

- It is concluded that, on usage of $4 \%$ of optical fibres the compressive strength increased. The compressive strength of concrete cube depends on diameter of the holes in the mould and the diameter of the optical fibre and it is directly proportion to its compressive strength [3].

- $\quad$ The compressive strength of Light Transmitting Concrete was found to be ranging between $20-23$ $\mathrm{N} / \mathrm{mm} 2$ with optical fibre specimen and with glass rods specimen the compressive strength was found to be ranging between $24-26 \mathrm{~N} / \mathrm{mm} 2$, which indicates that the concrete satisfies the compressive strength requirement for M20 grade concrete. The study concludes that the transparency of light is possible in concrete without affecting its compressive strength, as the optical fibres and glass rods act as fibre reinforcement thereby enhancing the strength and also enhances appearance[11].

- The amount of POFs has seriously influenced the compressive strength of the corresponding concrete. The much number the POFs are, the smaller the compressive strength is. So the transmissions cannot endless increase by way of endless increasing the number of POFs in concrete. Furthermore, the POFs have also reduced the anti-permeability of the concrete. Using the epoxy resin to seal the boundary of POFs and concrete, the smart transparent concrete's anti-permeability can be greatly improved [9].

\section{References}

[1]. Soumyajit Paul, Avik Dutta"Translucent Concrete", International Journal of Scientific and Research Publications, Volume 3, Issue 10, 2013, pp.

[2]. Aashish Ahuja, Khalid Mosalam, Tarek Zohdi"Computational Modeling of Translucent Concrete Panels", American Society of Civil Engineers, 2014.

[3]. R. Pradheepa,S. Krishnamoorthi"An Experimental Study on Translucent Concrete", International Journal for Scientific Research \& Development, Vol. 3, Issue 03, 2015, pp. 174-177

[4]. Saber Rahimi "Investigating the Use of Fibre Optic Sensors in Ferro concrete Structures", Technical Journal of Engineering and Applied Sciences, 2013, pp. 2796-2798

[5]. Bhavin Kashiyani, Varsha Raina, Jayeshkumar Pitroda, Bhavnaben Shah"A Study on Transparent Concrete: A Novel Architectural Material to Explore Construction Sector", International Journal of Engineering and Innovative Technology (IJEIT), Volume 2, Issue 8,2013, pp. 83-87

[6]. Anurag Shukla, Trushik Poriya, Jigar Zala "An Experimental Work On Light Transmitting Concrete", International Journal of Advance Engineering and Research Development (IJAERD) Volume 1, Issue 5, 2014.

[7]. F. Ansari " Practical Implementation of Optical Fibre Sensors in Civil Structural", Health Monitoring Journal of Intelligent Material Systems and Structures, 2007.

[8]. Shakir Ahmed Salih, Hasan Hamodi Joni, Safaa AdnanMohamed "Effect of Plastic Optical Fibre on Some Properties of Translucent Concrete", Eng. \&Tech.Journal, Vol. 32,Part (A), No.12,2014, pp. 2846-2861.

[9]. Jianping He, Zhi Zhou, Jinping Ou "Study on Smart Transparent Concrete Product and Its Performances", The 6th International Workshop on Advanced Smart Materials and Smart Structures Technology, ANCRiSST2011, Dalian, China, 2011.

[10]. Zhi Zhou, Ge Ou, Ying Hang, Genda Chen, Jinping Ou "Research and Development of Plastic Optical Fibre Based Smart Transparent Concrete", Center for Infrastructure Engineering Studies, Missouri Univ. of Science and Tech., Rolla,USA, 2009.

[11]. A. Momin, R. Kadiranaikar, Vakeel Jagirdar, Arshad Inamdar "Study on Light Transmittance of Concrete Using Optical Fibres and Glass Rods", International Conference on Advances in Engineering \& Technology (ICAET-2014),2014,pp.67-72

[12]. https://illumin.usc.edu/245/translucent-concrete-an-emerging-material/ 